\title{
RESEARCH
}

Open Access

\section{Combined therapy with adipose tissue- derived mesenchymal stromal cells and meglumine antimoniate controls lesion development and parasite load in murine cutaneous leishmaniasis caused by Leishmania amazonensis}

\begin{abstract}
Tadeu Diniz Ramos ${ }^{1,2}$, Johnatas Dutra Silva ${ }^{3}$, Alessandra Marcia da Fonseca-Martins', Juliana Elena da Silveira Pratti ${ }^{1}$, Luan Firmino-Cruz ${ }^{1}$, Diogo Maciel-Oliveira', Julio Souza Dos-Santos', João Ivo Nunes Tenorio ${ }^{4}$, Almair Ferreira de Araujo ${ }^{4}$, Célio Geraldo Freire-de-Lima², Bruno Lourenço Diaz ${ }^{4}$, Fernanda Ferreira Cruz ${ }^{3}$, Patricia Rieken Macedo Rocco ${ }^{3,5^{*}+}$ and Herbert Leonel de Matos Guedes ${ }^{1,6,7^{*}+}$ (1)
\end{abstract}

\begin{abstract}
Background: Leishmaniasis is a neglected disease caused by Leishmania spp. One of its characteristics is an imbalance of host immune responses to foster parasite survival. In this setting, mesenchymal stromal cells (MSCs) may be a viable therapeutic alternative, given their well-established immunomodulatory potential. In this study, we compared the effects of therapy with bone marrow (BM)- and adipose tissue (AD)-derived MSCs in leishmaniasis caused by Leishmania amazonensis in C57BL/6 mice. After determining the most effective MSC source, we then combined these cells with meglumine antimoniate (a pentavalent antimonial commonly used for the treatment of leishmaniasis) to treat the infected mice.

Methods: In vitro, co-culture of AD-MSCs and BM-MSCs with Leishmania amazonensis-infected macrophages was performed to understand the influence of both MSC sources in infected cells. In vivo, infected C57BL/6 mice were treated with phosphate-buffered saline (PBS), AD-MSCs and BM-MSCs, and then meglumine antimoniate was combined with MSCs from the most effective source.

(Continued on next page)
\end{abstract}

\footnotetext{
* Correspondence: prmrocco@biof.ufrj.br; herbert@biof.ufrj.br;

herbert@ioc.fiocruz.br

${ }^{\dagger}$ Patricia Rieken Macedo Rocco and Herbert Leonel de Matos Guedes share

senior authorships.

${ }^{3}$ Laboratório de Investigação Pulmonar, Instituto de Biofísica Carlos Chagas

Filho, Universidade Federal do Rio de Janeiro (UFRJ), Rio de Janeiro, Brazil

'Grupo de Imunologia e Vacinologia, Laboratório de Imunofarmacologia,

Instituto de Biofísica Carlos Chagas Filho, Universidade Federal do Rio de Janeiro (UFRJ), Rio de Janeiro, Brazil

Full list of author information is available at the end of the article
}

(c) The Author(s). 2020 Open Access This article is licensed under a Creative Commons Attribution 4.0 International License, which permits use, sharing, adaptation, distribution and reproduction in any medium or format, as long as you give appropriate credit to the original author(s) and the source, provide a link to the Creative Commons licence, and indicate if changes were made. The images or other third party material in this article are included in the article's Creative Commons licence, unless indicated otherwise in a credit line to the material. If material is not included in the article's Creative Commons licence and your intended use is not permitted by statutory regulation or exceeds the permitted use, you will need to obtain permission directly from the copyright holder. To view a copy of this licence, visit http://creativecommons.org/licenses/by/4.0/. The Creative Commons Public Domain Dedication waiver (http://creativecommons.org/publicdomain/zero/1.0/) applies to the data made available in this article, unless otherwise stated in a credit line to the data. 


\begin{abstract}
(Continued from previous page)
Results: In vitro, co-culture of Leishmania amazonensis-infected macrophages with BM-MSCs, compared to ADMSCs, led to a higher parasite load and lower production of nitric oxide. Fibroblasts grown in conditioned medium from co-cultures with AD-MSCs promoted faster wound healing. Despite a non-significant difference in the production of vascular endothelial growth factor, we observed higher production of tumor necrosis factor-a and interleukin (IL)-10 in the co-culture with AD-MSCs. In vivo, treatment of infected mice with BM-MSCs did not lead to disease control; however, the use of AD-MSCs was associated with partial control of lesion development, without significant differences in the parasite load. AD-MSCs combined with meglumine antimoniate reduced lesion size and parasite load when compared to PBS and AD-MSC groups. At the infection site, we detected a small production of IL-10, but we were unable to detect production of either IL-4 or interferon- $\gamma$, indicating resolution of infection without effect on the percentage of regulatory $T$ cells.
\end{abstract}

Conclusion: Combination treatment of cutaneous leishmaniasis with AD-MSCs and meglumine antimoniate may be a viable alternative.

Keywords: Leishmaniasis, Mesenchymal stromal cells, Adipose tissue-derived mesenchymal stromal cells, Meglumine antimoniate, Bone marrow-derived mesenchymal stromal cells, Parasite load

\section{Background}

Leishmaniasis is one of the most important neglected tropical diseases, ranking second in the number of deaths among parasitic diseases, surpassed only by malaria [1]. In Brazil, Leishmania (Leishmania) amazonensis is one of the main etiological agents of leishmaniasis. This species is part of the Leishmania mexicana complex and is an etiological agent for a broad spectrum of leishmaniasis pathologies, including diffuse cutaneous leishmaniasis $[2,3]$.

The first choice for the treatment of leishmaniasis is meglumine antimoniate, a pentavalent antimonial. Although these drugs were developed in the late 1940s, they still form the cornerstone of treatment for leishmaniasis worldwide [4]. These drugs inhibit the synthesis of ATP and GTP and interfere with the bioenergetics and the redox balance of the amastigote form of the parasite [5]. However, there are several issues associated with this treatment, such as daily parenteral dosing over a long period of time and high toxicity [6]. Alternative drugs for leishmaniasis treatment, such as amphotericin $B$ and pentamidines, present similar problems $[4,6,7]$. Therefore, the search for new therapeutic strategies with fewer side effects remains an area of active interest.

Mesenchymal stromal cells (MSCs) can be obtained from different tissues, such as the bone marrow, dental tissue, adipose tissue, and umbilical cord. These cells have been increasingly studied as a promising strategy for the treatment of various diseases [8-11], including parasitic diseases such as malaria [12] and Chagas disease [13-16].

Leishmania amazonensis uses mechanisms which subvert immune function in its favor to escape, survive, and establish infection [17-19]. MSCs have been described as cells with high immunomodulatory potential, regulating many factors and cell responses in different diseases
[20-22]. One of these functions is the stimulation of regulatory $\mathrm{T}$ cell $\left(\mathrm{T}_{\text {reg }}, \mathrm{CD}^{+} \mathrm{CD}^{+} 5^{+} \mathrm{FoxP}^{+}\right)$proliferation [23-25]. $\mathrm{T}_{\text {regs }}$ have been shown to play an essential role in lesion resolution in the C57BL/6 mouse model of Leishmania amazonensis infection [26].

The immunomodulatory potential of bone marrowderived mesenchymal stromal cells (BM-MSCs) was first tested in vitro using co-culture with Leishmania amazonensis-infected peritoneal macrophages. We observed increased intracellular amastigote counts in macrophages co-cultured with BM-MSC [27]. We then evaluated BMMSCs as a treatment in the BALB/c mouse model of Leishmania amazonensis infection [27], a well-established model for this parasite species [28, 29]. Although there was an increase in the number of $\mathrm{T}_{\text {regs }}$ upon treatment, this was insufficient to control the parasite load in this mouse model [27]. Still, it should be noted that, unlike in C57BL/6 mice, the role of $\mathrm{T}_{\text {regs }}$ in lesion resolution in infected BALB/c mice is still unclear. The increase in $T_{\text {regs }}$ observed in the $B A L B / c$ model suggested that treatment with MSCs in the C57BL/6 model could serve a greater purpose in the control of Leishmania amazonensis infection. Furthermore, the immunomodulatory properties of MSCs can vary according to their source [30-32]. Therefore, we hypothesized that MSCs derived from adipose tissue (AD-MSCs) or bone marrow (BM-MSCs) might exert different effects in a murine model of leishmaniasis.

The objective of our study was to evaluate the effects of bone marrow-derived mesenchymal stromal cells or adipose tissue-derived mesenchymal stromal cells in C57BL/6 mice infected with Leishmania amazonensis. For this purpose, we evaluated the in vitro influence of BM-MSCs versus AD-MSCs on Leishmania amazonensis-infected macrophages. Subsequently, the therapeutic effects of MSCs from both sources were analyzed in infected C57BL/6 mice. Finally, meglumine antimoniate 
was combined with MSCs from the most effective source and tested in these mice.

\section{Methods \\ Animals}

To carry out the experiments in this work, we used isogenic mice of the C57BL/6 strain, originally obtained from the Animal Laboratory of Universidade Federal Fluminense (UFF) at age 4 to 6 weeks. They were maintained in our own facilities under special temperature conditions $\left(23-25^{\circ} \mathrm{C}\right)$, a $12 / 12$-h light/dark cycle, and access to water and food ad libitum. At age 6 to 8 weeks, animals were used for experiments. All experimental protocols used in this work were approved by the Ethical Committees for Experimental Animal Use of Instituto de Biofísica Carlos Chagas Filho (CEUA IBCCF, protocol 157) and the Federal University of Rio de Janeiro Center of Health Sciences (CEUA-UFRJ, protocol 110/17).

\section{Parasites}

The parasites used in the experiments presented in this paper were Leishmania amazonensis (MHOM/BR/75/ Josefa strain) obtained by puncture of amastigotes from lesions of infected $\mathrm{BALB} / \mathrm{c}$ mice. The promastigotes were maintained at $26^{\circ} \mathrm{C}$ in M199 medium (Difco) containing $10 \%$ fetal bovine serum (FBS; Cultilab) until the fifth passage in culture to perform infection experiments. Infections were carried out with stationary phase culture, between the fourth and fifth days of culture.

\section{Preparation of MSCs}

For extraction of mesenchymal cells, male C57BL/6 mice (weight 20-25 g, age 8 weeks) were used as donors. The animals were anesthetized with intravenous ketamine ( $25 \mathrm{mg} / \mathrm{kg}$; Sigma) and xylazine ( $2 \mathrm{mg} / \mathrm{kg}$, Sigma) and euthanized with sevoflurane (Sevorane ${ }^{\circ}$, Abbott). With the aid of sterile forceps and scissors, an abdominal cut was made to remove the testicles. The fat located around the animals' epididymis was extracted and suspended in phosphate buffer (PBS). Then, the skin and muscles adjacent to the tibia and femur were removed.

To obtain AD-MSCs, the epididymal fat pads were collected, rinsed with PBS, transferred to a Petri dish, and cut into small pieces (approximately $0.2-0.8 \mathrm{~cm}^{2}$ ). The dissected pieces were washed with PBS, cut into smaller fragments, and subsequently digested with type I collagenase $(1 \mathrm{mg} / \mathrm{mL}$ in DMEM/10 mM HEPES) for $30-40 \mathrm{~min}$ at $37^{\circ} \mathrm{C}$. Any gross remnants that persisted after collagenase digestion were poured off between 1 and $3 \mathrm{~min}$, and the supernatant was transferred to a new tube containing fresh medium and centrifuged at $400 \times g$ for $10 \mathrm{~min}$ at $25^{\circ} \mathrm{C}$. The pellets were resuspended in 3.5 mL Dulbecco's modified Eagle's medium (DMEM; Invitrogen) containing $1 \%$ penicillin and streptomycin, with concentrations of $5000 \mathrm{IU} / \mathrm{mL}$ and $5000 \mu \mathrm{g} / \mathrm{mL}$, respectively (Gibco), 20\% of inactivated FBS (Invitrogen), and $15 \mathrm{mM}$ HEPES (Sigma), seeded in T25 flasks $(4 \mathrm{~mL}$ per flask), and incubated at $37^{\circ} \mathrm{C}$ in a humidified atmosphere containing $5 \% \mathrm{CO}_{2}$. On day 3 of culture, the medium was changed, and non-adherent cells were removed. Adherent cells exhibited similar proliferation rates and, upon reaching $80 \%$ confluence, they were passaged with a $0.25 \%$ trypsin-EDTA solution (Gibco) and maintained in DMEM with 10\% FBS (complete medium).

For the isolation of BM-MSCs, the epiphyses of the tibia and femur were cut, and the bones placed individually in sterile tips inside sterile, $15-\mathrm{mL}$ conical polystyrene tubes (TPP). The tubes were centrifuged at 1200 $\mathrm{rpm}$ for $5 \mathrm{~min}$ at room temperature. After centrifugation, the tips containing the bones were removed, and the pellets formed were suspended in low-glucose DMEM culture medium (Dulbecco's modified Eagle medium; Invitrogen) containing 20\% fetal bovine serum (Invitrogen) and $1 \%$ antibiotics (streptomycin and penicillin) (Gibco). The cell suspension was then plated in a 25 $\mathrm{cm}^{2}$ plastic culture bottle (TPP) and incubated at $37^{\circ} \mathrm{C}$ in a humidified atmosphere containing 5\% CO2.

Approximately $1 \times 10^{6}$ cells were characterized as MSCs at the third passage according to the consensus of the International Society of Cell Therapy [33].

\section{Characterization of MSCs}

Mesenchymal stromal cells were characterized by their ability to differentiate into osteocytes, chondrocytes, and adipocytes [33, 34]. Osteogenic differentiation was induced by culturing MSCs for up to 3 weeks in DMEM $10 \%$ FBS and $15 \mathrm{mM}$ HEPES (Sigma), supplemented with $10-5 \mathrm{mM} / \mathrm{L}$ dexamethasone (Sigma), $5 \mu \mathrm{g} / \mathrm{mL}$ ascorbic acid 2-phosphate (Sigma), and $10 \mathrm{mM} / \mathrm{L} \beta$ glycerolphosphate (Sigma) [34]. To observe calcium deposition, cultures were stained with Alizarin Red S (Nuclear). To induce adipogenic differentiation, MSCs were cultured with 10-8 M dexamethasone (Sigma), $2.5 \mu \mathrm{g} /$ $\mathrm{mL}$ insulin, and $50 \mu \mathrm{g} / \mathrm{mL}$ indomethacin (Sigma) [35]. Adipocytes were easily discerned from undifferentiated cells by phase-contrast microscopy. To further confirm their identity, cells were fixed with $4 \%$ paraformaldehyde with PBS and stained with Oil Red (Sigma) on day 21 of adipogenic differentiation. To induce chondrogenic differentiation, MSCs were cultured in DMEM supplemented with $10 \mathrm{ng} / \mathrm{mL}$ TGF- $\beta 1$ (Sigma), $50 \mathrm{nM}$ ascorbic acid 2-phosphate (Sigma), and $6.25 \mathrm{mg} / \mathrm{mL}$ insulin for 3 weeks. To confirm differentiation, cells were fixed with $4 \%$ paraformaldehyde in PBS for $1 \mathrm{~h}$ at room temperature and stained with Alcian Blue $\mathrm{pH} 2.5$ for detecting chondroblast secreted cell matrix (with chondrogenic differentiation) (data not shown). 
Flow cytometry was performed in a FACSCalibur system (Becton Dickinson), using commercially available antibodies and following standard procedures. Cells were plated in 96-well plates and then centrifuged for $4 \mathrm{~min}$ at $300 \times g, 4{ }^{\circ} \mathrm{C}$. Then, $10 \mu \mathrm{L}$ of anti-CD16/32 antibody were added to wells (Fc receptor blocker), remaining for $15 \mathrm{~min}$ at $4{ }^{\circ} \mathrm{C}$. At the end of incubation, the cells were washed with PBS $(100 \mu \mathrm{L} /$ well $)$, the plate was centrifuged at $300 \times g$ for $4 \mathrm{~min}$ at $4{ }^{\circ} \mathrm{C}$, and the supernatant was discarded. Subsequently, the cells were incubated with $10 \mu \mathrm{L}$ of solution containing anti-CD11b/FITC, anti-Sca1/APC, anti-CD44/Pecy5, anti-CD45/PE, anti-CD49/PE, and anti-CD34/EFluor660 antibodies for $30 \mathrm{~min}$ at $4{ }^{\circ} \mathrm{C}$ under light protection. Then, the cells were washed with $100 \mu \mathrm{L}$ of PBS and again centrifuged at $300 \times g$ for $4 \mathrm{~min}$ at $4{ }^{\circ} \mathrm{C}$. After discarding the supernatant, the cells were resuspended in $200 \mu \mathrm{L}$ of $1 \%$ PFA and transferred to FACS tubes containing $100 \mu \mathrm{L}$ of PBS. Data were analyzed using FlowJo software, version 8.7. The respective antibody isotypes of the abovementioned antibodies or samples of unlabeled cells were used as controls. An undifferentiated population of MSCs was used in all experiments.

\section{Peritoneal washing}

The C57BL/6 mice were anesthetized with sevoflurane (Sevorane, Abbott) and euthanized by terminal anesthesia with $\mathrm{CO}_{2}$. Washing of the peritoneal cavity was performed through a small incision in the cavity where $5 \mathrm{~mL}$ of RPMI-1640 (Sigma) was injected at $4{ }^{\circ} \mathrm{C}$ with the aid of a $24 \mathrm{G}$ needle and $5-\mathrm{mL}$ syringe. After homogenizing the liquid inside the animal's peritoneal cavity, the injected RPMI-1640 (Sigma) was collected with the aid of a syringe and needle into a $15-\mathrm{mL}$ tube and placed on ice $\left(4^{\circ} \mathrm{C}\right)$, to prevent cell adhesion to the tube. Shortly afterwards, the recovered volume was centrifuged for $5 \mathrm{~min}$ at $1500 \mathrm{rpm}, 4{ }^{\circ} \mathrm{C}$. The pellet was resuspended in $5 \mathrm{~mL}$ of RPMI-1640 (Sigma) without SFB, and the total cell count was obtained in a Neubauer chamber. $5 \times 10^{5}$ macrophages were plated in each well of the 24-well plate and, after $1 \mathrm{~h}$ (necessary for the cells to adhere to the plate surface), the RPMI without FBS was removed, the cells were washed 3 times with PBS at $37^{\circ} \mathrm{C}$, and $500 \mu \mathrm{L}$ of RPMI-1640 (Sigma) with $10 \%$ FBS (Invitrogen) was added to each well. After $24 \mathrm{~h}$, wells were washed with $\mathrm{PBS}$ at $37^{\circ} \mathrm{C}$ to purify the culture, removing the B1 lymphocytes and leaving only the macrophages.

\section{In vitro macrophage infection}

The plated macrophages were infected with $2.5 \times 10^{6}$ Leishmania amazonensis per well (5:1 ratio) for $4 \mathrm{~h}$. After this period, the macrophages were washed with PBS at $37{ }^{\circ} \mathrm{C}$ to remove any parasites that were not phagocytosed. Then, $500 \mu \mathrm{L}$ of RPMI-1640 (Sigma) 10\% fetal bovine serum (Cultilab) was added to the wells that did not receive co-culture, and $400 \mu \mathrm{L}$ of RPMI-1640 (Sigma) 10\% fetal bovine serum (Cultilab) to those that would receive co-culture later.

\section{Co-culture of macrophages with MSCs}

After infection with Leishmania amazonensis, $100 \mu \mathrm{L}$ of RPMI-1640 (Sigma) 10\% fetal bovine serum (Cultilab) containing $5 \times 10^{4}$ MSCs were added and left for $48 \mathrm{~h}$. The plate was washed 3 times with $\mathrm{PBS}$ at $37^{\circ} \mathrm{C}$, and the slides were stained with a Rapid Panoptic kit (LaborClin).

\section{Macrophage and amastigote count}

Panoptic-stained macrophages and MSCs were counted in groups of 50 cells per slide, under light microscopy (Olympus, CX31), at $\times 100$ magnification. Then, the percentage of infected cells, the mean of intracellular amastigotes per macrophage, and the total amount of amastigotes present in the slides were calculated. Representative images were obtained using a bright-field microscope (Olympus BX51) coupled to a digital camera (Olympus DP72) at $\times 1000$ magnification with the aid of the Cell F 3.1 software program (Olympus).

\section{Wound healing assay}

To perform the wound healing assay, $3 \times 10^{4} 3 \mathrm{~T} 3$ fibroblast cells were plated per well in a 96-well plate (TPP) and cultured with DMEM $+10 \%$ FBS at $37{ }^{\circ} \mathrm{C}$ and $5 \%$ $\mathrm{CO}_{2}$ until the monolayer of cells reach $90 \%$ of confluence. The culture medium was then changed to DMEM $+5 \%$ FBS to minimize cell proliferation, but keep it sufficient to prevent apoptosis and/or cell detachment.

After $24 \mathrm{~h}$, the wells were scratched, washed 3 times with PBS, and the culture mediums added. To evaluate the groups, each well received 50\% RPMI $+50 \%$ conditioned medium from the infected macrophage cultures. The plates were placed in an Incucyte ${ }^{\circ}$ ZOOM live-cell analysis system (Essen BioScience) and photographed every $20 \mathrm{~min}$ for $96 \mathrm{~h}$. Cell migration was analyzed in IncuCyte ${ }^{\circ}$ ZOOM 2015A software (Essen BioScience).

\section{In vivo infection}

After being received from the UFF vivarium, the animals were infected by subcutaneous injection of $20 \mu \mathrm{L}$ PBS containing $2 \times 10^{6}$ promastigotes of Leishmania amazonensis into the right hind footpad.

\section{Mesenchymal stromal cell treatment}

The transplanted cell dosage was based on pilot studies (data not shown). For this purpose, different doses of AD-MSCs and BM-MSCs have been tested and the lowest effective dosage was chosen to avoid possible side effects associated with higher doses (e.g., embolism). The 
mice received two doses of $1 \times 10^{5} \mathrm{AD}$-MSCs or $\mathrm{BM}$ MSCs to treat the infection, the first 15 days after infection and the second 21 days post infection. For instillation, the cells were detached from the culture bottles with $0.25 \%$ trypsin and resuspended in culture medium in $15-\mathrm{mL}$ conical polystyrene tubes. The tubes were centrifuged at $1200 \mathrm{RPM}$ for $5 \mathrm{~min}$ at room temperature, and the cell pellet was resuspended in $1 \mathrm{~mL}$ of saline $(\mathrm{NaCl} 0.9 \%)$. The quantification and determination of cell viability was performed by removing a $10-\mu \mathrm{L}$ aliquot of cells, subsequently diluted in $10 \mu \mathrm{L}$ of Trypan Blue $(0.02 \%)$ (Sigma). From this dilution, $10 \mu \mathrm{L}$ of cell suspension was removed and placed in a Neubauer chamber (Hausser Scientific) for cell counting. The number of viable cells was counted in the four quadrants and the appropriate dilution was obtained for the preparation of injections of $50 \mu \mathrm{L}$ of saline with $10^{5}$ cells in suspension.

\section{Administration of AD-MSCs or BM-MSCs}

$\mathrm{AD}-\mathrm{MSC}$ or $\mathrm{BM}-\mathrm{MSCs}$ were injected into the jugular vein, at a dose of $1 \times 10^{5}$. Animals were anesthetized with sevoflurane (Sevorane ${ }^{\bullet}$, Abbott), and the left jugular vein was dissected. A $0-5-\mathrm{mL}$ syringe and an insulin needle $(0.3 \times 13 \mathrm{~mm})$ were used to inject the cells in the cephalocaudal direction, and the vein was clamped for a few seconds to avoid any loss of blood or injected cells.

\section{Administration of meglumine antimoniate}

Treatment was begun on the 18th day after infection. On alternate days, the animals received $2 \mathrm{mg}$ of meglumine antimoniate $(100 \mathrm{mg} / \mathrm{kg})$ in $100 \mu \mathrm{L}$ of $\mathrm{PBS}$, at a concentration of $20 \mathrm{mg} / \mathrm{mL}$. The drug was injected intraperitoneally for 36 days.

\section{Clinical profile (lesion progression and parasite load)}

Lesion growth was monitored weekly with precision calipers (Mitutoyo). The measurement of the uninfected footpad was then deducted. On the predefined day after infection, mice were euthanized and the infected footpad of each animal was removed, placed in a 70\% alcohol solution for $1 \mathrm{~min}$, and individually weighed. Additionally, the draining popliteal lymph node was removed and placed in a vial with $1 \mathrm{~mL}$ of M199 medium. Footpad homogenates were obtained by manual maceration of the lesions with addition of $1 \mathrm{~mL}$ M199 medium and centrifuged for sedimentation of the heavier particles. The number of parasites in the footpads was determined by the limiting dilution assay (LDA). The macerates were diluted into 96-well culture plates (Jet Biofil, China) and incubated at $26^{\circ} \mathrm{C}$ for 15 days. Promastigote cultures were observed with an optical microscope (Olympus, Japan), and the last well containing promastigotes was observed and noted.

\section{Detection of markers by flow cytometry}

The cellularity of the popliteal lymph node macerate was quantified by counting in a Neubauer chamber $\left(1 \times 10^{6}\right.$ cells per well in 96-well plates) to characterize $\mathrm{T} \mathrm{CD} 4^{+}$ cells and $\mathrm{T}_{\text {regs }}\left(\mathrm{CD} 4^{+}, \mathrm{CD} 25^{+}\right.$, FoxP3 $\left.{ }^{+}\right)$. The plates were centrifuged at $300 \times g$ for $4 \mathrm{~min}$; $100 \mu \mathrm{L}$ of FACS buffer (PBS in 10\% FBS) was added to the pellet and the cells were centrifuged again.

For characterization of $\mathrm{T}_{\text {regs }}$, non-specific-labeling blockade with anti-FCR (1:100) incubation was done for $5 \mathrm{~min}$, followed by surface labeling with anti-CD3/ Pacific Blue (1:200), anti-CD4/Pecy7 (1:200), antiCD8/FITC (1:200), and anti-CD25/APC (1:200) antibodies for an additional $30 \mathrm{~min}$. The volume was made up to $200 \mu \mathrm{L}$ in FACS buffer; the cells were centrifuged, followed by fixation in kit fixation buffer (eBioscience) for $1 \mathrm{~h}$. Then, the cells were washed and $100 \mu \mathrm{L}$ of permeabilization buffer (eBioscience) was added to the pellet and incubated for $1 \mathrm{~h}$, followed by centrifugation. The cells were then incubated with anti-FCR for $20 \mathrm{~min}$ and intracellular labeling was performed with anti-FoxP3/AlexaFluor 488 (1:50) for $30 \mathrm{~min}$. The cells were washed in permeabilization buffer and resuspended in FACS buffer for flow cytometry analysis in a FACSCalibur system. The results were analyzed in FlowJo 8.7 software.

\section{Detection of cytokines by enzyme-linked immunosorbent assay (ELISA)}

Concentrations of the cytokines present in cell culture supernatants and the footpad homogenate supernatants were determined by the ELISA using commercial kits (BD OptEIA) according to the datasheet instructions. Recombinant murine TNF- $\alpha$, VEGF, IL10 , IFN- $\gamma$, and IL-4 were used to generate the standard curves. The minimum detection limits for these tests are $31.3 \mathrm{pg} / \mathrm{mL}$ for VEGF and IL-10 and 15.72 $\mathrm{pg} / \mathrm{mL}$ for TNF- $\alpha$, IFN- $\gamma$, and IL-4.

\section{Statistical analysis}

No formal sample size calculation was performed to determine the numbers of animals per group; the sample size was based on the experience of our laboratory in previous studies using this model of cutaneous leishmaniasis. All results were analyzed in GraphPad Prism v6.0 (GraphPad Software). The statistical significance of the differences between groups was determined by twoway ANOVA (for lesion progression and wound healing) followed by Dunn's test or one-way ANOVA (for all other comparisons) followed by Tukey's test. The values are expressed as mean \pm standard deviation. 


\section{Results}

Co-culture of Leishmania amazonensis-infected macrophages with BM-MSCs, but not with AD-MSCs, resulted in lower nitric oxide production and higher parasite load

To assess whether MSCs could alter the leishmanicidal capacity of $\mathrm{C} 57 \mathrm{BL} / 6$ macrophages, we infected macrophages with Leishmania amazonensis and cocultured them with BM-MSCs and AD-MSCs for 48 h. The cells were then stained (Fig. 1a-c) and the parasite load quantified. The presence of BM-MSCs increased the parasite load (total number of amastigotes) in C57BL/6 macrophages. However, the presence of AD-MSCs in the culture did not alter the parasite load per macrophage (Fig. 1d). The total number of amastigotes per well behaved similarly (Fig. 1e).

There was also a reduction in the nitric oxide concentration in infected macrophages co-cultured with BMMSCs compared to macrophages not co-cultured with MSCs co-culture and those co-cultured with AD-MSCs (Fig. 1f). These findings suggest that BM-MSCs induce macrophage susceptibility to Leishmania infection, which is likely associated with lower NO production, while the AD-MSCs do not affect the susceptibility of the macrophages.
Treatment with AD-MSCs promoted partial protection against lesion progression after Leishmania amazonensis inoculation in vivo

To evaluate whether treatment with BM-MSCs or ADMSCs would be effective in an in vivo infection, C57BL/6 mice were infected with Leishmania amazonensis and treated with two doses of BM-MSCs or AD-MSCs intravenously, as described in the "Methods" section. ADMSCs, but not BM-MSCs, were associated with less lesion progression compared to untreated control (Fig. 2a). However, treatment with MSCs (regardless of source) was not associated with any significant differences in parasite load 77 days after infection, when compared to control (Fig. 2b). These findings indicate that therapy with BM-MSCs is not beneficial in this model; however, AD-MSCs are able to partially control lesion progression.

Supernatant of infected macrophages cultured with ADMSC-conditioned medium induces faster healing

To understand the partial protection induced by treatment with AD-MSCs in vivo, a scratch wound healing assay was performed. 3T3 cells (fibroblast cell line) were cultured until $80 \%$ confluence, and the cell monolayer was scratched. The culture medium was switched out for either RPMI + supernatant of infected macrophages $(M \phi$ $+\mathrm{La})$ or RPMI + supernatant of infected macrophages
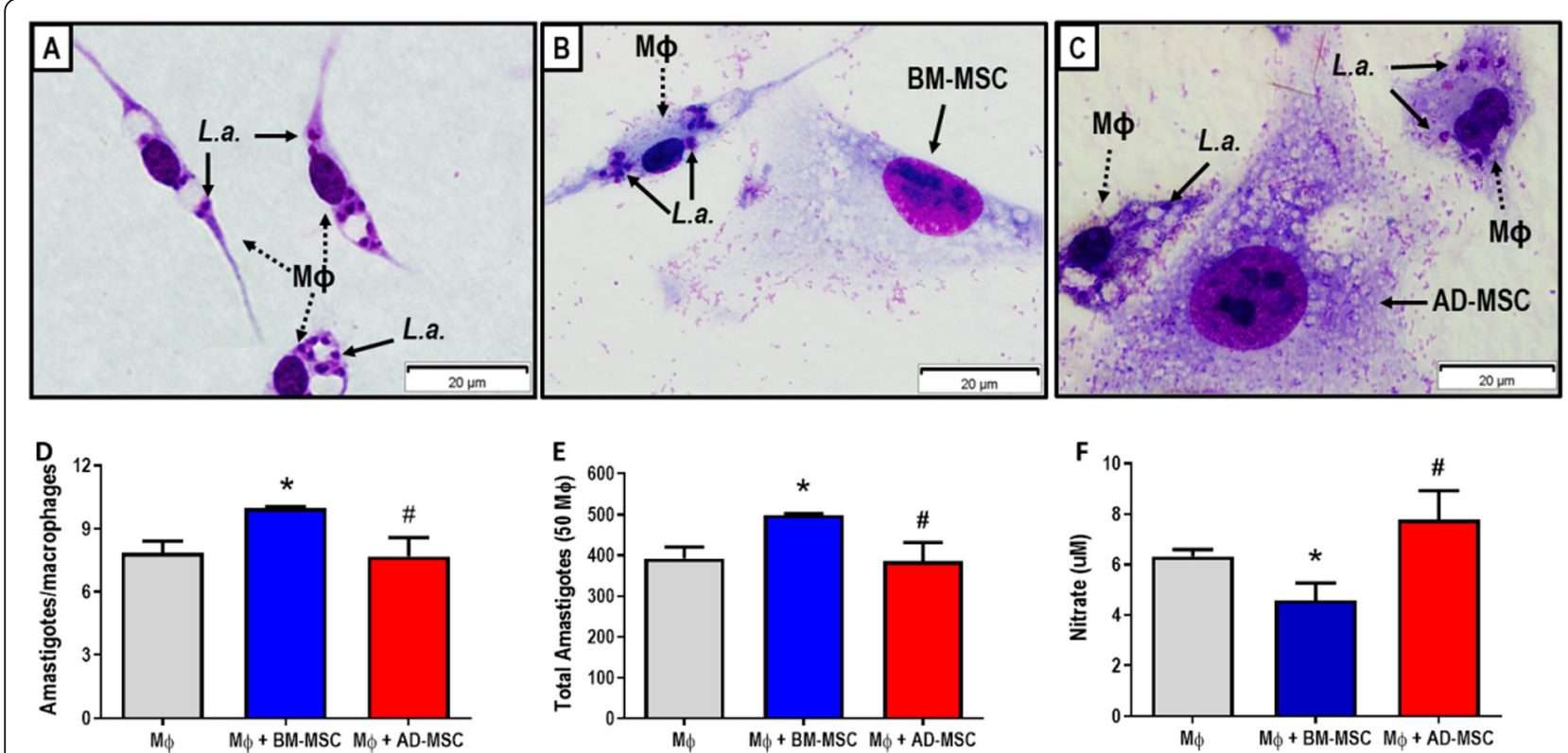

Fig. 1 In vitro infection of C57BL/6-derived peritoneal macrophages in co-culture with bone marrow (BM)-derived mesenchymal stromal cells (MSCs) or adipose tissue (AD)-derived MSCs. Representative images of peritoneal macrophages after infection with Leishmania amazonensis and macrophages and amastigote counts under the microscope. a Culture of infected macrophages. b Co-culture of infected macrophages with BM-MSCs. c Co-culture of infected macrophages with AD-MSCs. d Total amastigotes per macrophage. e Total amastigotes per well. f NO measurement. Rapid panoptic stain. Scale $20 \mu \mathrm{m}$. $(N=2)$ Representative of two independent experiments. Values show the mean \pm standard deviation. *Significantly different from infected Mf without co-culture (control) $(P<0.05)$. "Significantly different from infected Mf treated with BM-MSC $(P<0.05)$ 

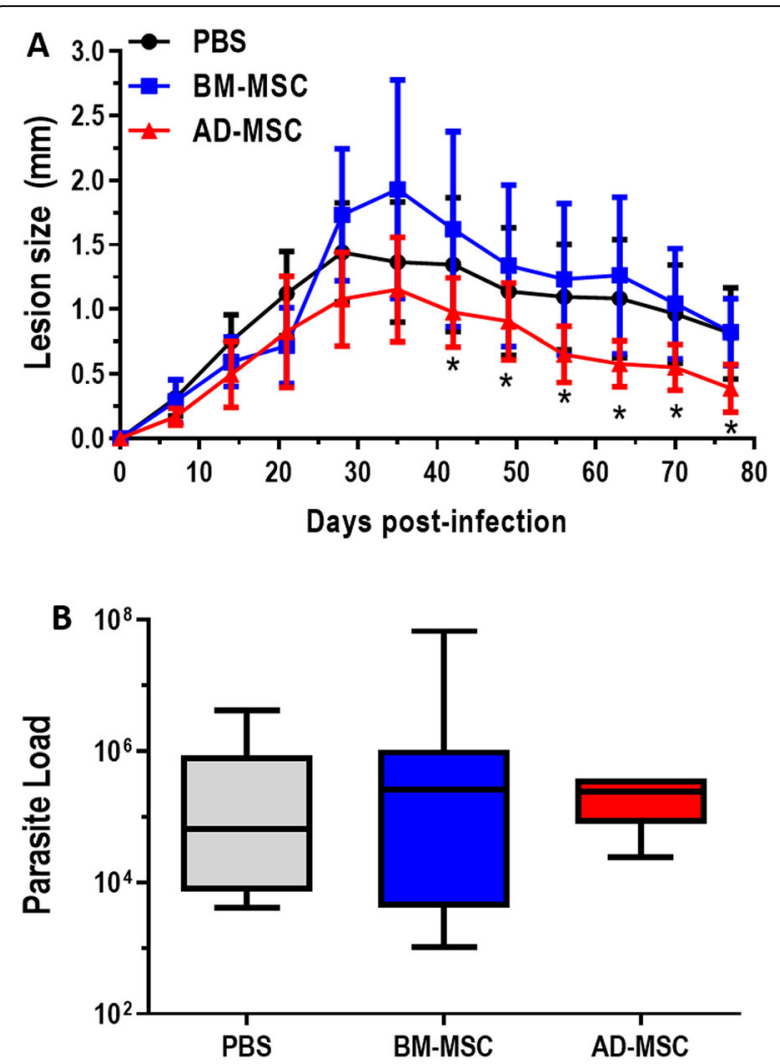

Fig. 2 Effect of BM-MSC and AD-MSC treatment on lesion progression in infected C57BL/6 mice. C57BL/6 mice were inoculated in the footpad with Leishmania amazonensis; treated either with PBS, BM-MSC, or ADMSC; and had lesion development measured with calipers on a weekly basis. After 77 days, the mice were euthanized, and the parasite load of the paw was determined by limiting dilution. a Analysis of lesion progression. $\mathbf{b}$ Analysis of parasite load in the paw. Representative of four independent experiments. $N=8$. Values show the mean \pm standard deviation. *Significantly different from PBS (control group) $(P<0.05)$

cultured with conditioned medium of MSCs $(\mathrm{M} \phi+\mathrm{La}+$ $\mathrm{AD}-\mathrm{MSC} \mathrm{SD}$ and $\mathrm{M} \phi+\mathrm{La}+\mathrm{BM}-\mathrm{MSC} \mathrm{SD})$. The wells where photographed every $20 \mathrm{~min}$ for $96 \mathrm{~h}$. We observed that cells treated with RPMI + supernatant of macrophages cultured with AD-MSC conditioned medium exhibited faster healing than wells treated with RPMI + supernatant of macrophages cultured with BM-MSC-conditioned medium (Fig. 3). We used a negative control and a positive control in the experiment (Additional file 1: FigureS1). This suggests that the molecules produced by AD-MSCs in contact with the infected macrophages induce faster healing.

\section{Co-culture of infected macrophages with AD-MSCs} increased the production of TNF- $\alpha$ and IL-10

Next, the co-culture supernatants were evaluated by ELISA to determine the effects of MSCs on macrophages. Co-culture of BM-MSCs and AD-MSCs with infected macrophages increased the production of TNF- $\alpha$
(Fig. 4a), IL-10 (Fig. 4b), and VEGF (Fig. 4c) in comparison to non-infected macrophages without MSC coculture. However, co-culture of infected macrophages with AD-MSCs was associated with an increase in the production of TNF- $\alpha$ and IL-10 (Fig. 4a, b) in relation to AD-MSCs with non-infected macrophages and BMMSC co-culture with both non-infected and infected macrophages. The infection did not modulate VEGF production. These results suggest that co-culture of macrophages with AD-MSCs makes the macrophages more responsive to infection, which could enhance the immune response and thus correlate with lesion control.

\section{Combination therapy with meglumine antimoniate and AD-MSCs conferred superior protection against Leishmania amazonensis infection in vivo}

As AD-MSCs conferred partial protection against injury and lesion progression, but did not affect parasite load in vivo, we combined cell therapy with meglumine antimoniate (pentavalent antimonial, PA) treatment to assess whether combination therapy would be more effective. Leishmania amazonensis-infected C57BL/6 mice were separated into 4 groups (PBS; AD-MSC; PA; $\mathrm{AD}-\mathrm{MSC}+\mathrm{PA})$. On days 15 and 21 post-infection, the mice received doses of AD-MSCs. On the 18th day after infection, the treatment with pentavalent antimonial was initiated and the mice continued to receive the drug on alternate days. Treatment with AD-MSC reduced lesion size in comparison with PBS, but no significant difference was observed in parasite load. Mice treated with PA reduced lesion size and parasite load, as expected, in comparison to PBS. However, mice treated with combined therapy (PA + AD-MSC) presented a further reduction of both lesion size (Fig. 5a) and parasite load (Fig. 5b) compared to all other groups. These results indicate that the combination of AD-MSCs and PA controls lesion development and parasite load better than AD-MSCs or PA alone.

\section{Mice treated with AD-MSCs and meglumine antimoniate exhibited a reduced inflammatory response}

Based on the capacity of MSC therapy to modulate the $\mathrm{T}$ cell response and population, we investigated the population of lymphocytes present in the draining lymph node. Lymph node cellularity was reduced in the group receiving combination treatment in comparison to the other groups (Fig. 6a). Although there were no significant differences in the percentages of $\mathrm{CD}^{+} \mathrm{T}$ cells (Fig. 6b) and $\mathrm{T}_{\text {regs }}\left(\mathrm{CD}^{+} \mathrm{CD}^{+} 5^{+}\right.$FoxP3 $^{+}$) (Fig. 6d) between groups, the reduced total cell number meant significantly lower numbers of $\mathrm{CD}^{+} \mathrm{T}$ cells and $\mathrm{T}_{\text {regs }}$ (Fig. 6c, e). This result suggests a decreased inflammatory response in the animals receiving combination therapy. We also evaluated the cytokine profile in the lesion. 


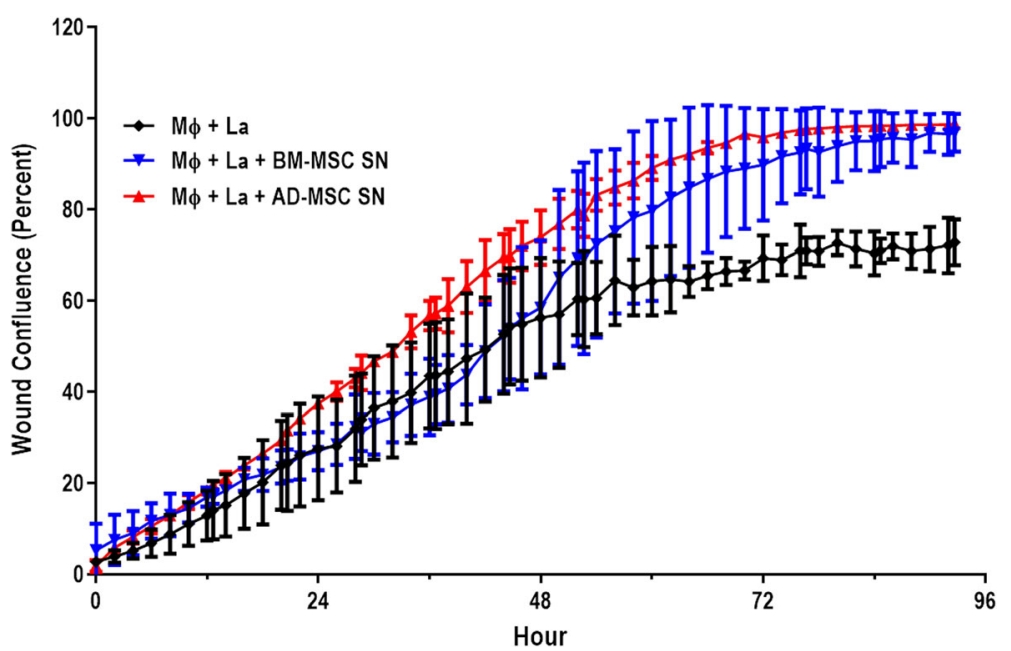

Fig. 3 Wound healing scratch assay. 3T3 cells were cultured until reaching $80 \%$ confluence. The cell monolayers were scratched, and the medium of the culture was changed as follows: RPMI (negative control—Supp, Fig. 1); DMEM + FBS (positive control—Supp, Fig. 1); RPMI + supernatant of infected macrophages (M $\phi+\mathrm{La})$; RPMI + supernatant of infected macrophages cultured with conditioned medium of MSCs (M $\phi+$ La + AD-MSC SD and M $\phi+$ $\mathrm{La}+\mathrm{BM}-\mathrm{MSC}$ SD). The scratch on the cell monolayer was photographed every $20 \mathrm{~min}$ for $96 \mathrm{~h}$ and analyzed by IncuCyte ZOOM $2015 \mathrm{~A}$. Values show the mean \pm standard deviation

Neither IFN- $\gamma$ (Fig. 7a) nor IL-4 (Fig. 7b) were detected in the PA and AD-MSC + PA groups, indicating resolution of infection. IL-10 was significantly lower in the PBS control group compared to the treated groups (Fig. 7c). These results indicate a faster healing process in the infection in all treated groups, but particularly in the group that received combination therapy.

\section{Discussion}

The discovery of treatments that can combat both the parasite and the immunopathology caused by leishmaniasis would greatly improve patient quality of life. Several studies have demonstrated the immunomodulatory role of MSCs in the control of inflammation. Thus, we hypothesized that MSC therapy could aid in the resolution of leishmaniasis through immunomodulation of the infection site and restoration of tissue homeostasis. MSCs have an immunomodulatory effect when used in the pro-inflammatory phase of sepsis, increasing the phagocytic capacity of immune cells [8] and causing macrophages of septic mice to produce more IL-10, shifting to a more anti-inflammatory phenotype, as well as improving organ function, which promotes a higher rate of survival [22]. In parasitic diseases, MSCs have been shown to decrease tissue inflammation in infections with Schistosoma japonicum [36] and Trypanosoma cruzi [14, 15], as well as decreasing parasitemia [16]. Furthermore, they have been shown to polarize macrophages towards a regulatory phenotype, resulting in increased levels of IL10 and IL-12 [37].
Leishmania amazonensis causes much less activation and production of cytokines by immune cells than do other species of Leishmania $[18,19]$. C57BL/6 mice infected with Leishmania amazonensis display a progressive phase of infection followed by partial resolution and chronic infection [38]. This closely resembles the profile observed in cases of human cutaneous leishmaniasis, which is typically a self-limiting disease [39, 40]. Parasites can still be found in healed lesions [40].

Although phenotypically similar, MSCs obtained from different tissues have different effects when used therapeutically, as demonstrated in studies of emphysema [30], sepsis [41], asthma [42], and bone regeneration [43]. Therefore, we investigated the effects of both bone marrow- and adipose tissue-derived MSCs. To understand the potential influence of MSCs on macrophages infected with Leishmania amazonensis, different cocultures were performed. Co-culture with AD-MSCs had no effect on in vitro infection (Fig. 1d, e). This has also been observed for Leishmania major infection, where C57BL/6 peritoneal macrophages exposed to AD-MSCs through transwell plates and then infected did not present any difference in the number of amastigotes compared to a control group without AD-MSC exposure [44]. In this study, however, infected macrophages cocultured with BM-MSCs displayed greater infection (Fig. 1d, e). This is in keeping with previous observations of our group in macrophages from BALB/c mice [27]. This result could be explained by the reduction in NO induced by this co-culture (Fig. 1f), as NO is directly involved in the killing of Leishmania parasites and 


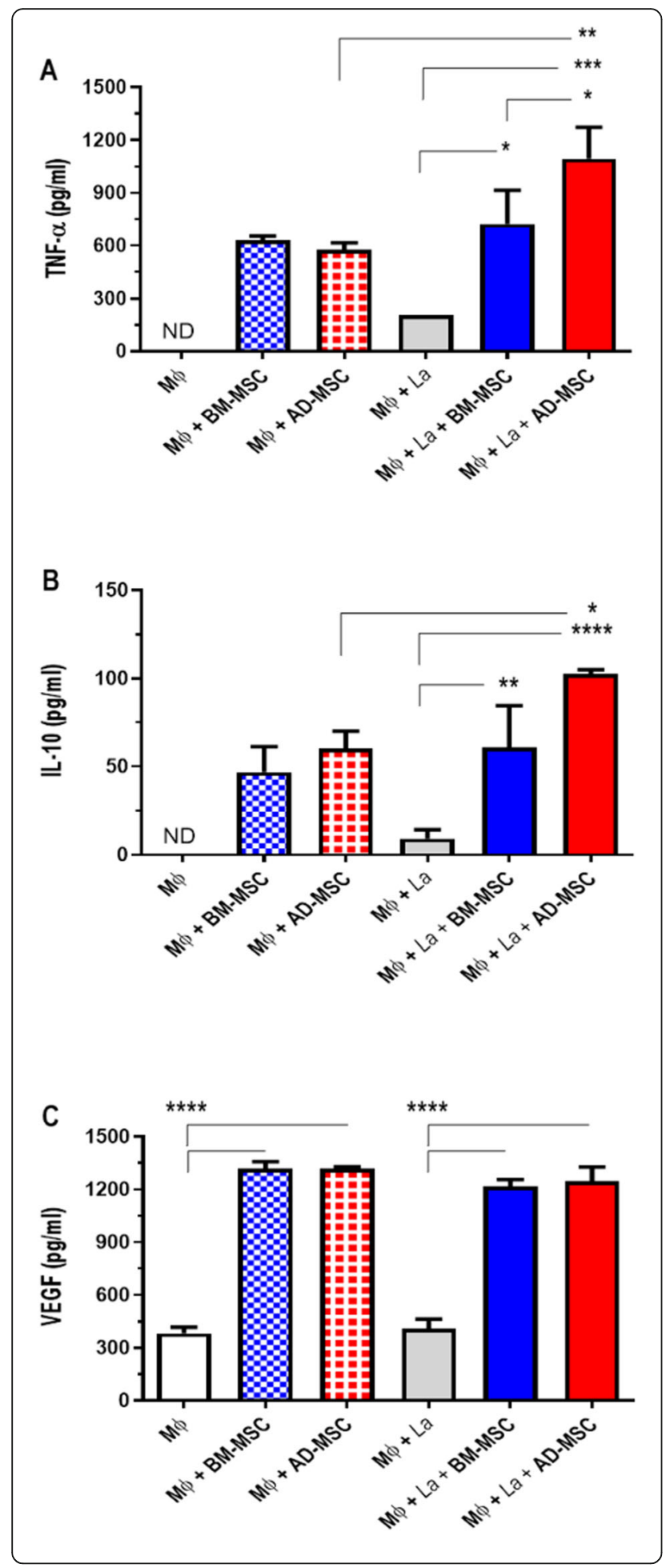

Fig. 4 Analysis of cytokine concentrations in cell culture supernatants. Concentrations of the cytokines TNF-a (a), IL-10 (b) and VEGF (c) present in supernatants of cell cultures were determined by enzyme-linked immunosorbent assay (ELISA) using commercial BD kits, according to the manufacturer's instructions. Groups: Macrophages (M $\phi)$; macrophages cocultured with BM-MSCs (M $\phi+$ BM-MSC); macrophages cocultured with AD-MSCs (M $\phi+$ AD-MSC); macrophages infected with Leishmania amazonensis ( $M \phi+$ La); macrophages infected with Leishmania amazonensis co-cultured with BM-MSCs (M $\phi+$ La + BM-MSC); macrophages infected with Leishmania amazonensis co-cultured with AD-MSCs (M $\phi+$ La + AD-MSC). Representative of two independent experiments. $N=3$. Values show the mean \pm standard deviation. ${ }^{*} P<0.05$, ${ }^{* *} P<0.01$, ${ }^{* *} P<$ 0.005 , and ${ }^{* * *} P<0.001$ indicate a significant difference between the groups. ND not detected

therefore is a key molecule in the control of the disease. Less NO production will thus decrease the leishmanicidal action of macrophages $[45,46]$. Another factor that can be related to the differences observed in parasite load is the production of cytokines. Co-culture with ADMSCs increased production of TNF- $\alpha$ and IL-10 as compared to co-culture with BM-MSCs (Fig. 4a and b). Thus, the two types of stromal cells had different effects on Leishmania amazonensis-infected macrophages, corroborating previously published work that has already shown that MSCs derived from different tissues produce different factors and effects [30, 42, 43, 47].

The success of wound healing has been associated with the resolution of inflammation. Chronic inflammation can lead to poor healing outcomes [48]. Therefore, the ability of MSCs to modulate the inflammatory response in wounds supports their favorable effect on the healing response. MSCs also enhance wound healing through paracrine effects, increasing the migration and proliferation of keratinocytes and fibroblasts $[49,50]$ and accelerating wound closure. In our study, AD-MSCs induced faster wound healing than BM-MSCs (Fig. 3). Our data are in accordance with Liu et al. [51] and Pelizzo et al. [52], who observed beneficial effects of ADMSCs on wound closure, as a result of better reepithelialization and thickening of granulation tissue, when compared to BM-MSCs.

Adipose-derived stromal vascular fraction cells (ADSVFs) are a cellular extract, rich in AD-MSCs, which can be easily obtained from adult (especially human) fat tissues [53]. AD-MSCs and AD-SFVs have been used successfully in several clinical applications, such as breast reconstruction [54], cartilage repair [55], androgenetic alopecia [56], atopic dermatitis [57], cutaneous wound healing [58], skin scars $[59,60]$, and modulation of cancer growth by repairing wounded tissue [61].

The effects of MSCs may differ depending on the route of administration. In previous work by our group, $\mathrm{BALB} / \mathrm{c}$ mice with leishmaniasis were treated with 

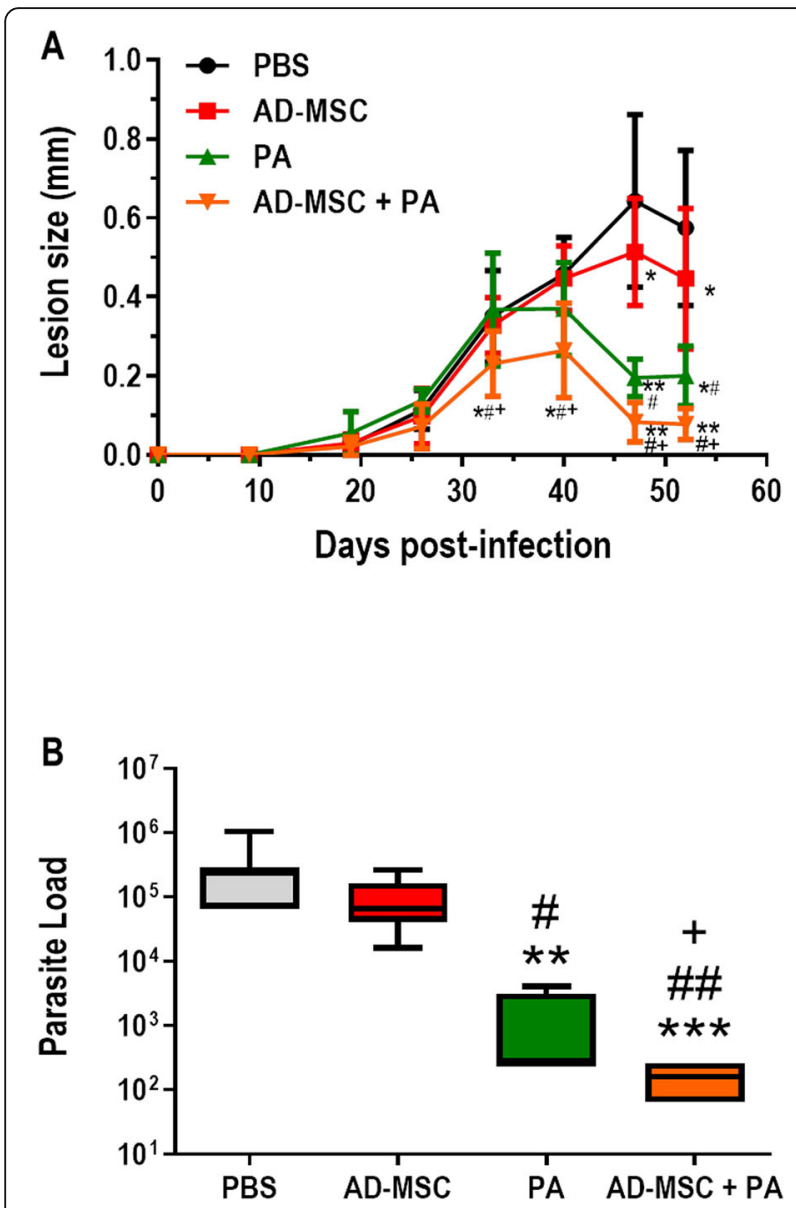

Fig. 5 Effect of combined therapy with AD-MSCs and a pentavalent antimonial on clinical profile. C57BL/6 mice were inoculated in the footpad with Leishmania amazonensis. On days 15 and 21 postinfection, the AD-MSC and AD-MSC + PA groups received AD-MSC and the control group was injected with PBS. On day 18, the PA and AD-MSC + PA groups started treatment with meglumine antimoniate, administered on alternate days until day 50 post-infection. After 52 days, the mice were euthanized and the parasite load was determined by limiting dilution. a Analysis of lesion progression. $\mathbf{b}$ Analysis of parasite load in the footpad. c Analysis of parasite lode in the popliteal lymph node. $N=9$ in the PBS group and $N=6$ in the other groups. Values show the mean \pm standard deviation. ${ }^{*} P<0.05$, ${ }^{*} P<0.01$, and ${ }^{* *} P<0.005$ indicate a significant difference between the groups in relation to the control (PBS); ${ }^{\#} P<0.05$ and ${ }^{\# \#} P<0.01$ indicate a significant difference between the groups in relation to the AD-MSC; ${ }^{+} P<0.05$ indicates a significant difference in the AD-MSC group in relation to the PA group

intravenous and intralesional administration of BMMSCs. Only the intravenous route resulted in beneficial effects on the immune response of infected animals, with a decrease in IFN- $\gamma$-producing $\mathrm{T} \mathrm{CD}^{+}$cells and an increase in IL-10-producing $\mathrm{T} \mathrm{CD}^{+}$and $\mathrm{T} \mathrm{CD}^{+}$populations, in addition to an increase in the population of $\mathrm{T}_{\text {reg }}$ cells [27]. This $\mathrm{T}_{\text {reg }}$ cell population has been shown to be essential for the control of Leishmania amazonensis infection in B6 mice [26]. Although our previous study with BALB/c mice yielded negative results for BM-MSC treatment, we assessed both BM-MSCs and AD-MSCs in the C57BL/6 model. However, while AD-MSC treatment was able to decrease lesion progression, conferring partial protection, treatment with BM-MSCs was again ineffective in this murine cutaneous leishmaniasis model (Fig. 2a). However, neither treatment managed to reduce parasite load in vivo (Fig. 2b). Thus, AD-MSCs appear to be more promising than BM-MSCs as a treatment for Leishmania amazonensis infection. AD-MSCs have also been demonstrated to have a beneficial effect in Leishmania major infection, inducing $\mathrm{CD}^{+} / \mathrm{CD}^{+} \mathrm{T}$ lymphocytes [62].

Based on the positive effects observed for AD-MSCs, it was hypothesized that the combination of AD-MSCs with conventional treatment (meglumine antimoniate) would "fight the parasite on two fronts," with PA killing the parasites and MSCs halting the inflammation caused by the infection. Indeed, the combination of the two treatments led to decreases both in lesion size (Fig. 5a) and in the number of parasites in the footpad (Fig. 5b). Although the group that received meglumine antimoniate alone did show reductions in lesion size and parasite load, mice that received combination therapy showed an even greater reduction in both parameters, which may be attributed to the beneficial effects of meglumine antimoniate in reducing the parasite load and AD-MSCs decreasing the inflammatory process and repairing the lesion through paracrine effects. The group treated with combination therapy also had a reduced number of total cells in the lymph node (Fig. 6a), which resulted in fewer $\mathrm{CD}^{+} \mathrm{T}$ cells (Fig. 6c), $\mathrm{CD}^{+} \mathrm{T}$ cells (Additional file 2: Figure $\mathrm{S} 2$ ), and $\mathrm{T}_{\text {regs }}$ (Fig. 6e).

The success of this therapy may be directly related to the reduced cellularity in the popliteal lymph node. $\mathrm{RAG}^{-/-}$mice infected with Leishmania major demonstrated susceptibility to infection due to the absence of $\mathrm{CD} 4+\mathrm{T}$ lymphocytes $[63,64]$. However, $\mathrm{MHCII}^{-1-}$, $\mathrm{RAG}^{-1-}$, and SCID mice are resistant to Leishmania amazonensis infection, with no macroscopic lesions, minimal cellular infiltrate, and reduced tissue parasite load [17], which suggests that the $\mathrm{CD}^{+} \mathrm{T}$ lymphocytes in the C57BL/6 mice contribute to the development of the lesion in cutaneous leishmaniasis caused by Leishmania amazonensis.

MSCs have the ability to induce $\mathrm{T}_{\text {regs }}$ [23-25]. It is well established that these cells are essential for tissue homeostasis, lesion progression, and parasite load in the C57BL/6 model of Leishmania amazonensis infection [26]. MSCs could act as a potential niche for $\mathrm{T}_{\text {regs }}$, promoting their generation, recruitment, phenotype maintenance, and function [23, 65]. Unlike what was observed in the BALB/c mice treated with BM-MSCs [27], in the present investigation, we did not find an 


\section{A}

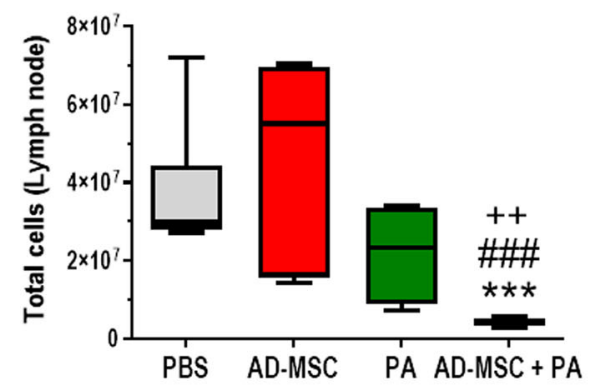

B

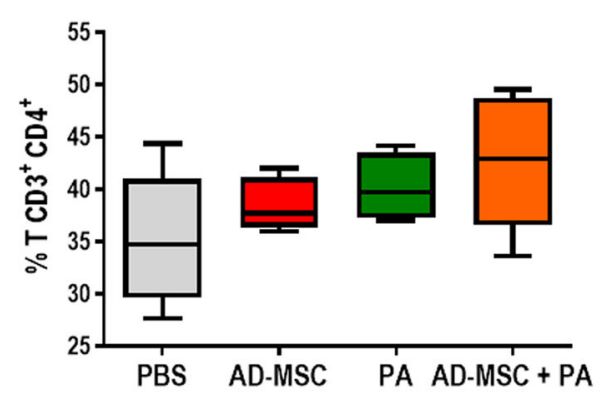

C

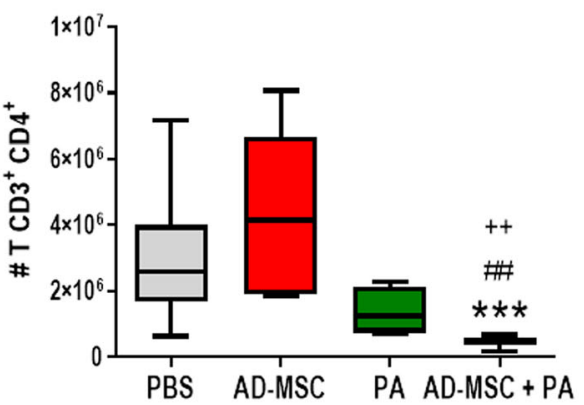

E

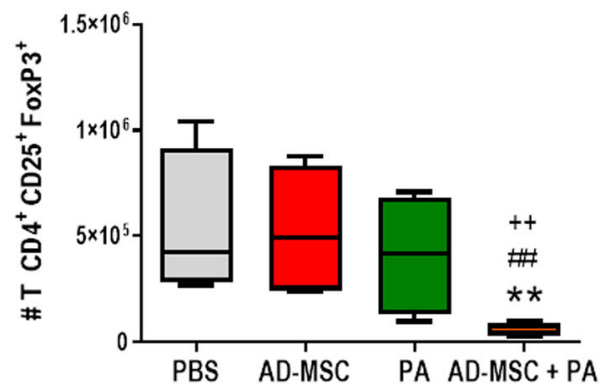

Fig. 6 Lymph node cell count and detection of $\mathrm{TCD}^{+}$and $\mathrm{T}_{\text {reg }}$ lymphocytes by flow cytometry (FACS). Cells were collected from the draining popliteal lymph node macerate, counted under a microscope ( $\times 4$ magnification), and analyzed by flow cytometry (FACS CANTO BD) for T CD4 ${ }^{+}$ and $\mathrm{T}_{\text {reg }}\left(\mathrm{CD}^{+} \mathrm{CD}^{2} 5^{+} \mathrm{FoxP3}^{+}\right)$lymphocyte expression after 52 days of infection. Results shown as percentage and total population of cells positive for these markers in $\mathrm{CD}^{+}$marker-positive lymphocytes. a Total number of lymph node cells. b Percentage of CD4 ${ }^{+} \mathrm{T}$ lymphocytes. $\mathbf{c}$ Total $C D 4^{+} T$ lymphocyte population. $\mathbf{d}$ Percentage of $\mathrm{T}_{\text {reg }}$ lymphocytes. e $\mathrm{T}_{\text {reg }}$ lymphocyte population. Values show the mean \pm standard deviation for each group. ${ }^{*} P<0.05 * *, P<0.01$, and ${ }^{* *} P<0.005$ indicate a significant difference between the groups in relation to the control

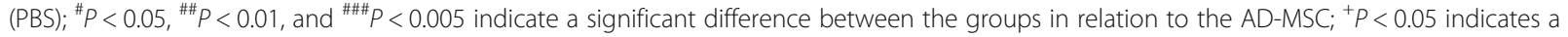
significant difference in the AD-MSC group in relation to the PA group

increase in $\mathrm{T}_{\text {regs }}$ in the AD-MSC treatment group. Furthermore, in the combined treatment group, which had less lesion progression and a lower parasitic load, the total number of $\mathrm{T}_{\text {regs }}$ was the lowest in relation to the other treatment groups (Fig. $6 \mathrm{~d}$ ). We believe that a lower parasite burden leads to less induction of $\mathrm{T}_{\text {regs. }}$. Therefore, the mechanism underlying protection in the $\mathrm{AD}$ -
MSC treatment group does not appear to be related to $\mathrm{T}_{\text {regs. }}$.

Several studies have demonstrated that AD-MSC treatment can modulate the production of several cytokines. For example, AD-MSC treatment decreases IL-4 levels, ameliorating allergic airway inflammation in a mouse model of asthma [24] and increasing survival in 


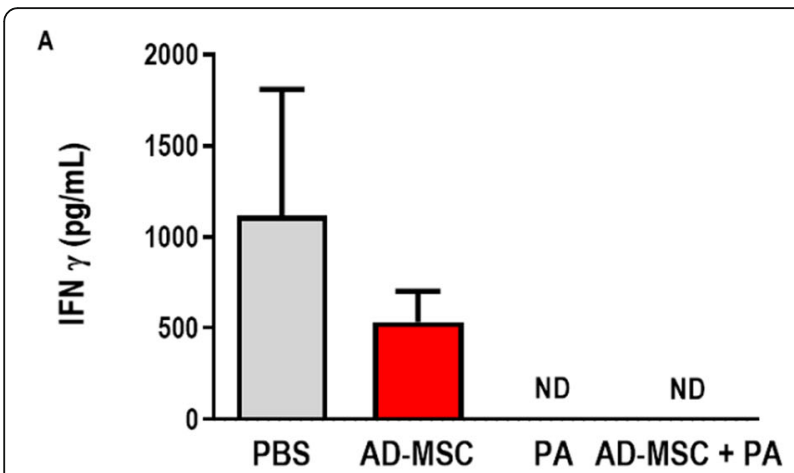

B

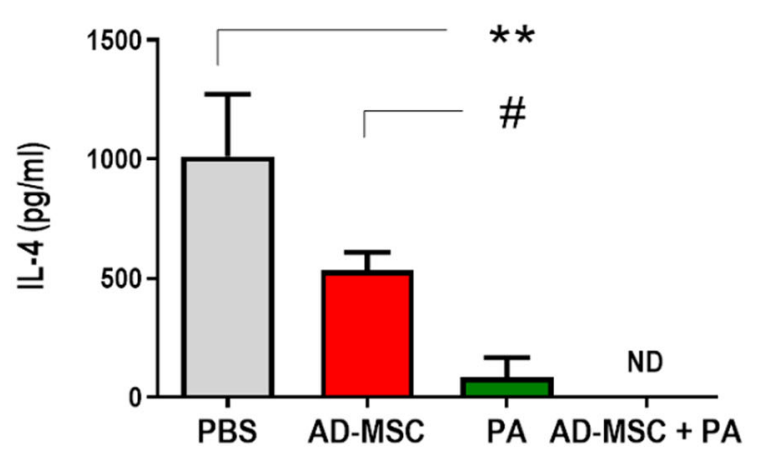

C

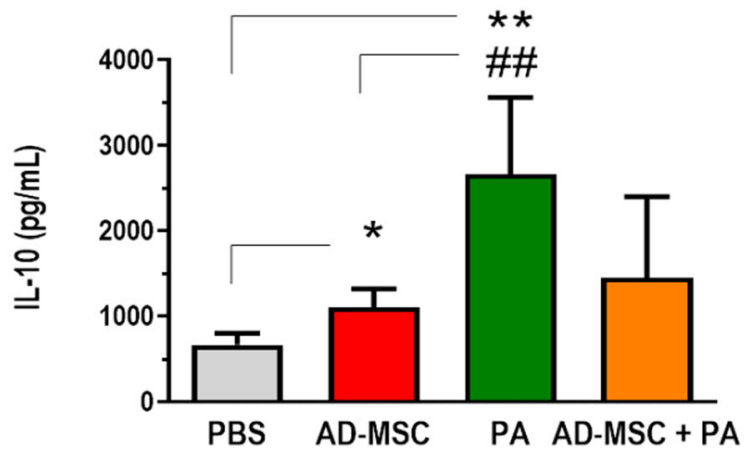

Fig. 7 Analysis of cytokine concentrations at the site of infection. Concentrations of the cytokines IFN- $\gamma(\mathbf{a}), \mathrm{IL}-4$ (b), and IL-10 (c) present in supernatants of paw homogenates were determined by enzyme-linked immunosorbent assay (ELISA) using commercial BD kits, according to manufacturer instructions. ${ }^{*} P<0.05$ and ${ }^{* *} P<0.01$ indicate a significant difference in relation to the control (PBS); ${ }^{\#} P<$ 0.05 and ${ }^{\# \#} P<0.01$ indicate a significant difference between groups in relation to the AD-MSC group. ND not detected

mice with sepsis [41]. Mello [16] demonstrated that ADMSC treatment in mice with Trypanosoma cruzi infection decreases IFN- $\gamma$ levels in the heart, increasing protection against heart damage. The production of cytokines, such as IL-4, IFN- $\gamma$, and IL-10, plays a key role in the susceptibility or resistance to leishmaniasis. In Leishmania major infection, the model that is the major example of the Th1-/Th2-response dichotomy, IFN- $\gamma$, a Th1 cytokine, plays an essential role in the control of parasite growth [66, 67]. Mice deficient in IFN- $\gamma$ fail to cure Leishmania major infection [68]. Pinheiro and Rossi-Bergmann [69] have shown their role of these cytokines in controlling disease progression in the late phase of Leishmania amazonensis infection. In addition, several studies have shown the importance of IFN- $\gamma$ in stimulating cytotoxic mechanisms that promote parasite elimination [70, 71]. IL-4, however, is one of the major cytokines involved in induction of the Th2-type response, together with IL-13. IL-4 production is associated with susceptibility to Leishmania major infection [72, 73] and to Leishmania amazonensis infection [74]. Production of this cytokine inhibits expression of the $\beta 2$ chain of the IL-12 receptor, leading to development of a Th2 response and, hence, susceptibility to infection [75]. In the present study, no production of IFN- $\gamma$ (Fig. 7a) or IL-4 (Fig. 7b) was detected at the site of infection after treatment with either combination therapy or meglumine antimoniate alone. This suggests that the proinflammatory response had already resolved at the time of euthanasia in both groups, and is consistent with previous findings in Chagas disease [16] and sepsis [41]. However, in Leishmania major infection, an enhancement of the Th1 response was observed after treatment with ADMSCs; the treated mice exhibited increases in IFN- $\gamma$ and TNF- $\alpha$ production, which was unexpected [62].

IL-10 has several effects on cutaneous leishmaniasis, one of which is the capability to suppress NO production and leishmanicidal activity in macrophages, leading to the suppression of Th1 responses [76]. In mice infected with Leishmania amazonensis, IL-10 partially contributes to the generation of immunodeficient responses [77, 78], which is the main factor by which susceptibility is increased in mice co-infected with phlebotomine saliva [79]. However, the role of IL-10 in Leishmania amazonensis infection is still poorly understood. The data obtained by cytokine measurement in the present study suggests increased production of IL-10 in the groups which received combination therapy or the pentavalent antimonial alone (Fig. 7c). This elevated IL-10 production may be due to the resolution of inflammatory response at the site of infection; as both lesion progression and parasite load are already controlled by this point, its presence would be to decrease proinflammatory factors, such as IFN- $\gamma$.

Mesenchymal stromal cells derived from adipose tissue appear to be the more promising option for the treatment of Leishmania amazonensis infection in a murine model, as opposed to MSCs derived from the bone marrow. AD-MSCs conferred partial protection during lesion development, while BM-MSCs did not provide any benefits in terms of lesion progression or parasite load. Furthermore, in vitro, infected macrophages co-cultured with AD-MSCs did not have their infection worsened, 
unlike macrophages co-cultured with BM-MSCs. Our data for Leishmania amazonensis infection support the longstanding notion that, although there are no significant phenotypic differences among MSCs from different sources $[80,81]$, they do indeed elicit different host responses [30, 41, 42].

This study has some limitations that should be addressed. First, a specific model of leishmaniasis was used; thus, whether results would be similar in other models is unknown. Second, further in vivo studies combining MSC therapy with macrophages should be performed, even though some reports have demonstrated a good relationship between the in vitro immunomodulatory capacity of MSCs and their in vivo immunomodulatory capacity $[82,83]$.

In summary, the combination of cell therapy using $\mathrm{AD}-\mathrm{MSCs}$ and chemotherapy with pentavalent antimonials seems to potentiate the healing process in an experimental model of cutaneous leishmaniasis. This combination was able to reduce lesion progression, parasite loads, cellularity in draining lymph nodes, and cytokine production. To our knowledge, this is the first time a combined regimen of cell therapy and conventional treatment has been investigated in a model of Leishmania infection. This novel line of therapy warrants further investigation.

\section{Conclusion}

Taken together, our data suggest that mesenchymal stromal cells derived from adipose tissue are an alternative and feasible therapy for cutaneous leishmaniasis caused by Leishmania amazonensis, especially as an adjunct to conventional treatment with meglumine antimoniate. AD-MSCs conferred greater protection against injury by reducing parasite load, mitigating the inflammatory response, and accelerating the healing process. Its combination with a pentavalent antimonial constituted an effective dual therapy, treating both the parasitic infestation itself and the immunopathology caused by Leishmania amazonensis.

\section{Supplementary information}

Supplementary information accompanies this paper at https://doi.org/10. 1186/s13287-020-01889-z.

\footnotetext{
Additional file 1 : Figure S1. Wound healing scratch assay controls. 3 T3 cells were cultured until reaching $80 \%$ confluence. The cell monolayers were scratched, and the medium of the culture was changed as follows: RPMI (negative control); DMEM + FBS (positive control). Values show the mean \pm standard deviation.

Additional file $\mathbf{2}$ : Figure $\mathbf{S 2}$. Detection of $\mathrm{T} C D 8^{+}$lymphocytes by flow cytometry (FACS). Cells were collected from the draining popliteal lymph node macerate, counted under a microscope (40x magnification), and analyzed by flow cytometry (FACS CANTO BD) for T CD $8^{+}$lymphocyte expression after 52 days of infection. Results shown as percentage and total population of cells positive for these markers in $\mathrm{CD}^{+}$markerpositive lymphocytes. (A) Percentage of $\mathrm{CD}^{+} \mathrm{T}$ lymphocytes; (B) Total
}

$\mathrm{CD}^{+} \mathrm{T}$ lymphocyte population; Values show the mean \pm standard deviation for each group. ${ }^{*} P<0.05,{ }^{* *} P<0.01$ indicate a significant difference between the groups in relation to the control (PBS); \# $P<0.05$, \#\# $P<0.01$, \#\#\# $P<0.005$ indicate a significant difference between the groups in relation to $A D-M S C ;+P<0.05$ indicates a significant difference in the AD-MSC group in relation to the PA group.

\section{Abbreviations}

MSCs: Mesenchymal stromal sells; BM-MSCs: Bone marrow-derived mesenchymal stromal cells; AD-MSCs: Adipose tissue-derived mesenchymal stromal cells; NO: Nitric oxide; VEGF: Vascular endothelial growth factor; IL-

10: Interleukin-10; TNF-a: Tumor necrosis factor-alpha; IL-4: Interleukin 4; IFNү: Interferon-gamma; ATP: Adenosine triphosphate; GTP: Guanosine triphosphate; Treg: Regulatory T lymphocyte; PBS: Phosphate buffer; DMEM: Dulbecco's minimal essential medium; $\mathrm{CO}_{2}$ : Carbon dioxide; CD: Cluster of differentiation; LDA: Limiting dilution assay; ELISA: Enzymelinked immunosorbent assay; FACS: Fluorescence-activated cell sorting; $T$ $\mathrm{CD}^{+}$: $\mathrm{CD}^{+}{ }^{+}$T lymphocyte; T CD8 ${ }^{+}: \mathrm{CD}^{+} \mathrm{T}$ lymphocyte; M $\phi$ : Macrophages; PA: Pentavalent antimonial; IL-12: Interleukin-12; MHC: Major

histocompatibility complex; IL-13: Interleukin-13

\section{Acknowledgements}

We thank Mrs. Moira Elizabeth Schottler and Mr. Filippe Vasconcellos for their assistance in editing the manuscript.

\section{Authors' contributions}

TDR conceived and designed the study, performed in vitro and in vivo experiments, analyzed and interpreted the in vitro and in vivo data, and drafted the manuscript; JDS conceived the experiments, acquired the MSCs, and analyzed the cytometry data; AMFM performed surgery and cytometry for the in vivo experiments; JESP performed surgery and data acquisition for the in vivo experiments; LFC acquired the cells and performed cytometry for the in vivo experiments; DMO performed surgery for the in vivo experiments; JSS performed surgery for the in vivo experiments; JINT analyzed data from the wound healing assay; AFA acquired data from the wound healing assay; CGFL revised the manuscript; BLD interpreted data and revised the manuscript; FFC acquired data and revised the manuscript; PRMR conceived the study, interpreted the data, and revised the manuscript; HLMG contributed to the conception and design of the work, interpretation of data, and revision of the manuscript. All authors approved the submission of the manuscript.

\section{Funding}

The work was funded by the Conselho Nacional de Desenvolvimento Científico e Tecnológico (CNPq) and the Fundação Carlos Chagas Filho de Amparo à Pesquisa do Estado do Rio de Janeiro (FAPERJ).

\section{Availability of data and materials}

The datasets during and/or analyzed during the current study are available from the corresponding author on reasonable request.

\section{Ethics approval and consent to participate}

All experimental protocols used in this work were approved by the Ethics Committees for Experimental Animal Use of Instituto de Biofísica Carlos Chagas Filho (CEUA IBCCF, protocol no. 157) and the Federal University of Rio de Janeiro Center of Health Sciences (CEUA-UFRJ, protocol no. 110/17).

\section{Consent for publication}

Not applicable

\section{Competing interests}

The authors declare that they have no competing interests.

\section{Author details}

'Grupo de Imunologia e Vacinologia, Laboratório de Imunofarmacologia, Instituto de Biofísica Carlos Chagas Filho, Universidade Federal do Rio de Janeiro (UFRJ), Rio de Janeiro, Brazil. 'Laboratório de Imunomodulação, Instituto de Biofísica Carlos Chagas Filho, Universidade Federal do Rio de Janeiro (UFRJ), Rio de Janeiro, Brazil. 'Laboratório de Investigação Pulmonar, Instituto de Biofísica Carlos Chagas Filho, Universidade Federal do Rio de 
Janeiro (UFRJ), Rio de Janeiro, Brazil. "Laboratório de Inflamação, Instituto de Biofísica Carlos Chagas Filho, Universidade Federal do Rio de Janeiro (UFRJ), Rio de Janeiro, Brazil. ${ }^{5}$ National Institute of Science and Technology for Regenerative Medicine, Rio de Janeiro, Rio de Janeiro, Brazil. ${ }^{6}$ UFRJ Campus Duque de Caxias Professor Geraldo Cidade, Duque de Caxias, Rio de Janeiro, Brazil. 'aboratório Interdisciplinar de Pesquisas Médicas, Instituto Oswaldo Cruz/FIOCRUZ, Rio de Janeiro, Brazil.

\section{Received: 27 May 2020 Revised: 6 August 2020}

\section{Accepted: 17 August 2020 Published online: 31 August 2020}

\section{References}

1. Afrin F, Khan I, Hemeg HA. Leishmania-host interactions-an epigenetic paradigm. Front Immunol. 2019;10:492.

2. Silveira FT, Lainson R, Corbett CE. Clinical and immunopathological spectrum of American cutaneous leishmaniasis with special reference to the disease in Amazonian Brazil: a review. Mem Inst Oswaldo Cruz. 2004;99:239-51.

3. Schriefer A, Guimarães LH, Machado PR, Lessa M, Lessa HA, Lago E, et al. Geographic clustering of leishmaniasis in northeastern Brazil. Emerg Infect Dis. 2009;15:871-6.

4. Tiuman TS, Santos AO, Ueda-Nakamura T, Filho BP, Nakamura CV. Recent advances in leishmaniasis treatment. Int J Infect Dis. 2011;15:871-6.

5. Frézard F, Demicheli C, Ribeiro RR. Pentavalent antimonials: new perspectives for old drugs. Molecules. 2009;14:2317-36.

6. Gontijo B, de Carvalho Mde L. Leishmaniose tegumentar americana [American cutaneous leishmaniasis]. Rev Soc Bras Med Trop. 2003:36:71-80.

7. Mishra J, Saxena A, Singh S. Chemotherapy of leishmaniasis: past, present and future. Curr Med Chem. 2007;14:1153-69.

8. Mei SH, Haitsma JJ, Dos Santos CC, Deng Y, Lai PF, Slutsky AS, et al. Mesenchymal stem cells reduce inflammation while enhancing bacterial clearance and improving survival in sepsis. Am J Respir Crit Care Med. 2010; 182:1047-57.

9. Abreu SC, Antunes MA, Pelosi P, Morales MM, Rocco PR. Mechanisms of cellular therapy in respiratory diseases. Intensive Care Med. 2011;37:1421-31.

10. Silva JD, Lopes-Pacheco M, Paz AHR, Cruz FF, Melo EB, de Oliveira MV, et al. Mesenchymal stem cells from bone marrow, adipose tissue, and lung tissue differentially mitigate lung and distal organ damage in experimental acute respiratory distress syndrome. Crit Care Med. 2018;46:e132-40.

11. Kang SH, Kim MY, Eom YW, Baik SK. Mesenchymal stem cells for the treatment of liver disease: present and perspectives. Gut Liver. 2020;14:306-15.

12. Thakur RS, Tousif $S$, Awasthi $V$, et al. Mesenchymal stem cells play an important role in host protective immune responses against malaria by modulating regulatory T cells. Eur J Immunol. 2013;43:2070-7.

13. Soares MB, Lima RS, Rocha LL, Takyia CM, Pontes-de-Carvalho L, de Carvalho $A C$, et al. Transplanted bone marrow cells repair heart tissue and reduce myocarditis in chronic chagasic mice. Am J Pathol. 2004;164:441-7.

14. Goldenberg RC, Jelicks LA, Fortes FS, Weiss LM, Rocha LL, Zhao D, et al. Bone marrow cell therapy ameliorates and reverses chagasic cardiomyopathy in a mouse model. J Infect Dis. 2008;197:544-7.

15. Jasmin JLA, Koba W, Tanowitz HB, Mendez-Otero R, Campos de Carvalho $A C$, et al. Mesenchymal bone marrow cell therapy in a mouse model of chagas disease. Where do the cells go? PLoS Negl Trop Dis. 2012;6:e1971.

16. Mello DB, Ramos IP, Mesquita FC, Brasil GV, Rocha NN, Takiya CM, et al. Adipose tissue-derived Mesenchymal stromal cells protect mice infected with Trypanosoma cruzi from cardiac damage through modulation of antiparasite immunity. PLoS Negl Trop Dis. 2015;9:e0003945.

17. Soong $\mathrm{L}$, Chang $\mathrm{CH}$, Sun J, Longley BJ Jr, Ruddle $\mathrm{NH}$, Flavell RA, et al. Role of CD4+ T cells in pathogenesis associated with Leishmania amazonensis infection. J Immunol. 1997:158:5374-83.

18. Xin L, Li Y, Soong L. Role of interleukin-1beta in activating the CD11c(high) CD45RB- dendritic cell subset and priming Leishmania amazonensis-specific CD4+ T cells in vitro and in vivo. Infect Immun. 2007;75:5018-26.

19. Vargas-Inchaustegui $D A$, Xin L, Soong L. Leishmania braziliensis infection induces dendritic cell activation, ISG15 transcription, and the generation of protective immune responses. J Immunol. 2008;180:7537-45.

20. Németh K, Leelahavanichkul A, Yuen PS, Mayer B, Parmelee A, Doi K, et al. Bone marrow stromal cells attenuate sepsis via prostaglandin $E(2)$ dependent reprogramming of host macrophages to increase their interleukin-10 production. Nat Med. 2009;15:42-9.

21. Xu L, Gong Y, Wang B, Shi K, Hou Y, Wang L, et al. Randomized trial of autologous bone marrow mesenchymal stem cells transplantation for hepatitis B virus cirrhosis: regulation of Treg/Th17 cells. J Gastroenterol Hepatol. 2014:29:1620-8.

22. Lombardo E, van der Poll T, DelaRosa O, Dalemans W. Mesenchymal stem cells as a therapeutic tool to treat sepsis. World J Stem Cells. 2015;7:368-79.

23. Di lanni M, Del Papa B, De loanni M, Moretti L, Bonifacio E, Cecchini D, et al. Mesenchymal cells recruit and regulate T regulatory cells. Exp Hematol. 2008:36:309-18

24. Cho KS, Park MK, Kang SA, et al. Adipose-derived stem cells ameliorate allergic airway inflammation by inducing regulatory $T$ cells in a mouse model of asthma. Mediat Inflamm. 2014;2014:436476.

25. Vasilev G, Ivanova M, Ivanova-Todorova $E$, et al. Secretory factors produced by adipose mesenchymal stem cells downregulate Th17 and increase Treg cells in peripheral blood mononuclear cells from rheumatoid arthritis patients. Rheumatol Int. 2019;39(5):819-26.

26. Ji J, Masterson J, Sun J, Soong L. CD4+CD25+ regulatory T cells restrain pathogenic responses during Leishmania amazonensis infection. J Immunol. 2005:174:7147-53.

27. Pereira JC, Ramos TD, Silva JD, et al. Effects of bone marrow mesenchymal stromal cell therapy in experimental cutaneous leishmaniasis in BALB/C mice induced by Leishmania amazonensis. Front Immunol. 2017:8:893.

28. Terabe M, Wakana S, Katakura K, Onodera T, Matsumoto Y, Ito M. Influence of $\mathrm{H} 2$ complex and non- $\mathrm{H} 2$ genes on progression of cutaneous lesions in mice infected with Leishmania amazonensis. Parasitol Int. 2004;53:217-21.

29. Pereira BA, Alves CR. Immunological characteristics of experimental murine infection with Leishmania (Leishmania) amazonensis. Vet Parasitol. 2008;158: 239-55.

30. Antunes MA, Abreu SC, Cruz FF, et al. Effects of different mesenchymal stromal cell sources and delivery routes in experimental emphysema. Respir Res. 2014;15:118.

31. Hao T, Chen J, Zhi S, Zhang Q, Chen G, Yu F. Comparison of bone marrowvs. adipose tissue-derived mesenchymal stem cells for attenuating liver fibrosis. Exp Ther Med. 2017:14:5956-64.

32. Takahashi A, Nakajima H, Uchida K, et al. Comparison of mesenchymal stromal cells isolated from murine adipose tissue and bone marrow in the treatment of spinal cord injury. Cell Transplant. 2018;27:1126-39.

33. Dominici M, Le Blanc K, Mueller I, et al. Minimal criteria for defining multipotent mesenchymal stromal cells. The International Society for Cellular Therapy position statement. Cytotherapy. 2006:8:315-7.

34. Nombela-Arrieta C, Ritz J, Silberstein LE. The elusive nature and function of mesenchymal stem cells. Nat Rev Mol Cell Biol. 2011:12:126-31.

35. Phinney DG, Kopen G, Isaacson RL, Prockop DJ. Plastic adherent stromal cells from the bone marrow of commonly used strains of inbred mice: variations in yield, growth, and differentiation. J Cell Biochem. 1999;72:57085.

36. Xu H, Qian H, Zhu W, et al. Mesenchymal stem cells relieve fibrosis of Schistosoma japonicum-induced mouse liver injury. Exp Biol Med (Maywood). 2012;237:585-92.

37. Maggini J, Mirkin G, Bognanni I, Holmberg J, Piazzón IM, Nepomnaschy I, et al. Mouse bone marrow-derived mesenchymal stromal cells turn activated macrophages into a regulatory-like profile. PLoS One. 2010;5 e9252.

38. Pratti JE, Ramos TD, Pereira JC, da Fonseca-Martins AM, Maciel-Oliveira D, Oliveira-Silva G, et al. Efficacy of intranasal LaAg vaccine against Leishmania amazonensis infection in partially resistant C57BI/6 mice. Parasit Vectors. 2016;9:534.

39. Mendonça MG, de Brito ME, Rodrigues EH, Bandeira V, Jardim ML, Abath FG. Persistence of leishmania parasites in scars after clinical cure of American cutaneous leishmaniasis: is there a sterile cure? J Infect Dis. 2004;189:1018-23.

40. Silveira FT, Lainson R, De Castro Gomes CM, Laurenti MD, Corbett CE. Immunopathogenic competences of Leishmania (V.) braziliensis and L. (L.) amazonensis in American cutaneous leishmaniasis. Parasite Immunol. 2009; 31:423-31.

41. Ou H, Zhao S, Peng Y, Xiao X, Wang Q, Liu H, et al. Comparison of bone marrow tissue- and adipose tissue-derived mesenchymal stem cells in the treatment of sepsis in a murine model of lipopolysaccharide-induced sepsis. Mol Med Rep. 2016;14:3862-70.

42. Abreu SC, Antunes MA, Xisto DG, Cruz FF, Branco VC, Bandeira E, et al. Bone marrow, adipose, and lung tissue-derived murine mesenchymal stromal cells release different mediators and differentially affect airway and lung parenchyma in experimental asthma. Stem Cells Transl Med. 2017;6:1557-67. 
43. Freitas GP, Lopes HB, Souza ATP, Oliveira PGFP, Almeida ALG, Souza LEB, et al. Cell therapy: effect of locally injected mesenchymal stromal cells derived from bone marrow or adipose tissue on bone regeneration of rat calvarial defects. Sci Rep. 2019;9:13476.

44. Dameshghi S, Zavaran-Hosseini A, Soudi S, Shirazi FJ, Nojehdehi S, Hashemi SM. Mesenchymal stem cells alter macrophage immune responses to Leishmania major infection in both susceptible and resistance mice. Immunol Lett. 2016;170:15-26.

45. Bogdan $C$, Röllinghoff $M$, Diefenbach $A$. The role of nitric oxide in innate immunity. Immunol Rev. 2000;173:17-26.

46. Loría-Cervera EN, Sosa-Bibiano El, Villanueva-Lizama LE, Van Wynsberghe NR, Canto-Lara SB, Batún-Cutz JL, et al. Nitric oxide production by Peromyscus yucatanicus (Rodentia) infected with Leishmania (Leishmania) mexicana. Mem Inst Oswaldo Cruz. 2013;108:172-7.

47. Maguire G. The safe and efficacious use of secretome from fibroblasts and adipose-derived (but not bone marrow-derived) mesenchymal stem cells for skin therapeutics. J Clin Aesthet Dermatol. 2019;12:E57-69.

48. Xu J, Wu W, Zhang L, Dorset-Martin W, Morris MW, Mitchell ME, et al. The role of microRNA-146a in the pathogenesis of the diabetic wound-healing impairment: correction with mesenchymal stem cell treatment. Diabet. 2012;61:2906-12.

49. Smith AN, Willis E, Chan VT, Muffley LA, Isik FF, Gibran NS, et al. Mesenchymal stem cells induce dermal fibroblast responses to injury. Exp Cell Res. 2010;316:48-54

50. Lee SH, Jin SY, Song JS, Seo KK, Cho KH. Paracrine effects of adipose-derived stem cells on keratinocytes and dermal fibroblasts. Ann Dermatol. 2012;24: 136-43.

51. Liu X, Wang Z, Wang R, Zhao F, Shi P, Jiang Y, et al. Direct comparison of the potency of human mesenchymal stem cells derived from amnion tissue, bone marrow and adipose tissue at inducing dermal fibroblast responses to cutaneous wounds. Int J Mol Med. 2013;31:407-15.

52. Pelizzo G, Avanzini MA, Icaro Cornaglia A, Osti M, Romano P, Avolio L, et al. Mesenchymal stromal cells for cutaneous wound healing in a rabbit model: pre-clinical study applicable in the pediatric surgical setting. J Transl Med. 2015;13:219.

53. Mojallal A, Lequeux C, Shipkov C, Rifkin L, Rohrich R, Duclos A, et al. Stem cells, mature adipocytes, and extracellular scaffold: what does each contribute to fat graft survival? Aesthet Plast Surg. 2011;35:1061-72.

54. Gentile P, Casella D, Palma E, Calabrese C. Engineered fat graft enhanced with adipose-derived stromal vascular fraction cells for regenerative medicine: clinical, histological and instrumental evaluation in breast reconstruction. J Clin Med. 2019;8:504.

55. Pak J, Lee JH, Kartolo WA, Lee SH. Cartilage regeneration in human with adipose tissue-derived stem cells: current status in clinical implications. Biomed Res Int. 2016;2016:4702674.

56. Gentile P, Scioli MG, Cervelli V, Orlandi A, Garcovich S. Autologous micrografts from scalp tissue: trichoscopic and long-term clinical evaluation in male and female androgenetic alopecia. Biomed Res Int. 2020;2020: 7397162.

57. Shin TH, Kim HS, Choi SW, Kang KS. Mesenchymal stem cell therapy for inflammatory skin diseases: clinical potential and mode of action. Int J Mol Sci. 2017;18:244.

58. Enciso N, Avedillo L, Fermín ML, Fragío C, Tejero C. Cutaneous wound healing: canine allogeneic ASC therapy. Stem Cell Res Ther. 2020;11:261.

59. Gentile P, De Angelis B, Pasin M, Cervelli G, Curcio CB, Floris M, et al. Adipose-derived stromal vascular fraction cells and platelet-rich plasma: basic and clinical evaluation for cell-based therapies in patients with scars on the face. J Craniofac Surg. 2014;25:267-72.

60. Gentile P, Scioli MG, Bielli A, Orlandi A, Cervelli V. Comparing different nanofat procedures on scars: role of the stromal vascular fraction and its clinical implications. Regen Med. 2017;12:939-52.

61. Gentile P, Garcovich S. Concise review: adipose-derived stem cells (ASCs) and adipocyte-secreted exosomal microRNA (A-SE-miR) modulate cancer growth and promote wound repair. J Clin Med. 2019;8:855.

62. Zanganeh E, Soudi S, Zavaran Hosseini A, Khosrojerdi A. Repeated intravenous injection of adipose tissue derived mesenchymal stem cells enhances Th1 immune responses in Leishmania major-infected BALB/C mice. Immunol Lett. 2019;216:97-105.

63. Locksley RM, Reiner SL, Hatam F, Littman DR, Killeen N. Helper T cells without CD4: control of leishmaniasis in CD4-deficient mice. Science. 1993; 261:1448-51.
64. Johnson LM, Scott P. STAT1 expression in dendritic cells, but not T cells, is required for immunity to Leishmania major. J Immunol. 2007;178:7259-66.

65. Maccario R, Podestà M, Moretta A, Cometa A, Comoli P, Montagna D, et al. Interaction of human mesenchymal stem cells with cells involved in alloantigen-specific immune response favors the differentiation of CD4+ Tcell subsets expressing a regulatory/suppressive phenotype. Haematologica. 2005;90:516-25.

66. Scott P. IFN-gamma modulates the early development of Th1 and Th2 responses in a murine model of cutaneous leishmaniasis. J Immunol. 1991; 147:3149-55.

67. Liew FY, Wei XQ, Proudfoot L. Cytokines and nitric oxide as effector molecules against parasitic infections. Philos Trans R Soc Lond Ser B Biol Sci. 1997;352:1311-5.

68. Wang ZE, Zheng S, Corry DB, Dalton DK, Seder RA, Reiner SL, et al. Interferon gamma-independent effects of interleukin 12 administered during acute or established infection due to Leishmania major. Proc Natl Acad Sci U S A. 1994;91:12932-6.

69. Pinheiro RO, Rossi-Bergmann B. Interferon-gamma is required for the late but not early control of Leishmania amazonensis infection in C57BI/6 mice. Mem Inst Oswaldo Cruz. 2007;102:79-82.

70. Gorak PM, Engwerda CR, Kaye PM. Dendritic cells, but not macrophages, produce IL-12 immediately following Leishmania donovani infection. Eur J Immunol. 1998;28:687-95.

71. Lemos MP, Esquivel F, Scott P, Laufer TM. MHC class II expression restricted to CD8alpha+ and CD11b+ dendritic cells is sufficient for control of Leishmania major. J Exp Med. 2004;199:725-30.

72. Launois P, Swihart KG, Milon G, Louis JA. Early production of IL-4 in susceptible mice infected with Leishmania major rapidly induces IL-12 unresponsiveness. J Immunol. 1997;158:3317-24.

73. Launois P, Maillard I, Pingel S, Swihart KG, Xénarios I, Acha-Orbea H, et al. IL4 rapidly produced by $\mathrm{V}$ beta $4 \mathrm{~V}$ alpha $8 \mathrm{CD} 4+\mathrm{T}$ cells instructs Th2 development and susceptibility to Leishmania major in BALB/C mice. Immunity. 1997;6:541-9.

74. Guimarães ET, Santos LA, Ribeiro dos Santos R, Teixeira MM, dos Santos WL, Soares MB. Role of interleukin-4 and prostaglandin E2 in Leishmania amazonensis infection of BALB/c mice. Microbes Infect 2006;8:1219-1226.

75. Himmelrich $H$, Launois $P$, Maillard I, Biedermann T, Tacchini-Cottier F, Locksley RM, et al. In BALB/C mice, IL-4 production during the initial phase of infection with Leishmania major is necessary and sufficient to instruct Th2 cell development resulting in progressive disease. J Immunol. 2000;164: 4819-25.

76. Cunha FQ, Moncada S, Liew FY. Interleukin-10 (IL-10) inhibits the induction of nitric oxide synthase by interferon-gamma in murine macrophages. Biochem Biophys Res Commun. 1992;182:1155-9.

77. Jones DE, Buxbaum LU, Scott P. IL-4-independent inhibition of IL-12 responsiveness during Leishmania amazonensis infection. J Immunol. 2000; 165:364-72.

78. Ji J, Sun J, Soong L. Impaired expression of inflammatory cytokines and chemokines at early stages of infection with Leishmania amazonensis. Infect Immun. 2003;71:4278-88.

79. Norsworthy NB, Sun J, Elnaiem D, Lanzaro G, Soong L. Sand fly saliva enhances Leishmania amazonensis infection by modulating interleukin-10 production. Infect Immun. 2004;72:1240-7.

80. Kern S, Eichler H, Stoeve J, Klüter H, Bieback K. Comparative analysis of mesenchymal stem cells from bone marrow, umbilical cord blood, or adipose tissue. Stem Cells. 2006;24:1294-301.

81. Jin HJ, Bae YK, Kim M, Kwon SJ, Jeon HB, Choi SJ, et al. Comparative analysis of human mesenchymal stem cells from bone marrow, adipose tissue, and umbilical cord blood as sources of cell therapy. Int J Mol Sci. 2013;14: 17986-8001.

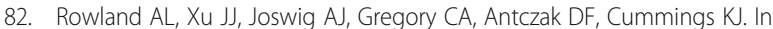
vitro MSC function is related to clinical reaction in vivo. Stem Cell Res Ther. 2018;9:295.

83. Zhang C, Lin Y, Liu Q, He J, Xiang P, Wang D, et al. Growth differentiation factor 11 promotes differentiation of MSCs into endothelial-like cells for angiogenesis. J Cell Mol Med. 2020. https://doi.org/10.1111/jcmm.15502.

\section{Publisher's Note}

Springer Nature remains neutral with regard to jurisdictional claims in published maps and institutional affiliations. 